\title{
Transparent hydrogel with enhanced water retention capacity by introducing highly hydratable salt
}

\section{Citation}

Bai, Yuanyuan, Baohong Chen, Feng Xiang, Jinxiong Zhou, Hong Wang, and Zhigang Suo. 2014. "Transparent Hydrogel with Enhanced Water Retention Capacity by Introducing Highly Hydratable Salt." Appl. Phys. Lett. 105 (15) (October 13): 151903. Portico. doi:10.1063/1.4898189.

\section{Published Version}

doi:10.1063/1.4898189

\section{Permanent link}

http://nrs.harvard.edu/urn-3:HUL.InstRepos:13943562

\section{Terms of Use}

This article was downloaded from Harvard University's DASH repository, and is made available under the terms and conditions applicable to Open Access Policy Articles, as set forth at http:// nrs.harvard.edu/urn-3:HUL.InstRepos:dash.current.terms-of-use\#OAP

\section{Share Your Story}

The Harvard community has made this article openly available.

Please share how this access benefits you. Submit a story.

\section{Accessibility}




\title{
Transparent hydrogel with enhanced water retention capacity by introducing highly hydratable salt
}

\author{
Yuanyuan Bai, ${ }^{1}$ Baohong Chen, ${ }^{2}$ Feng Xiang, ${ }^{1}$ Jinxiong Zhou, ${ }^{2}$ Hong Wang, ${ }^{1, a)}$ and Zhigang \\ $\mathrm{Suo}^{3, \mathrm{a})}$ \\ ${ }^{1}$ School of Electronics and Information Engineering, Electronic Materials Research Laboratory, Xi'an \\ Jiaotong University, Xi'an 710049, China \\ ${ }^{2}$ State Key Laboratory for Strength and Vibration of Mechanical Structures, International Center for \\ Applied Mechanics and School of Aerospace, Xi'an Jiaotong University, Xi'an 710049, China \\ ${ }^{3}$ School of Engineering and Applied Sciences, Kavli Institute of Bionano Science and Technology, \\ Harvard University, Cambridge, Massachusetts 02138, USA
}

\begin{abstract}
Polyacrylamide hydrogels containing salt as electrolyte have been used as highly stretchable transparent electrodes in flexible electronics, but those hydrogels are easy to dry out due to water evaporation. Targeted, we try to enhance water retention capacity of polyacrylamide hydrogel by introducing highly hydratable salts into the hydrogel. These hydrogels show enhanced water retention capacity in different level. Specially, polyacrylamide hydrogel containing high content of lithium chloride can retain over $70 \%$ of its initial water even in environment with relative humidity of only $10 \%$ RH. The excellent water retention capacities of these hydrogels will make more applications of hydrogels become possible.
\end{abstract}

\footnotetext{
a) Electronic mail: hwang@mail.xjtu.edu.cn, suo@seas.harvard.edu.
} 
In many applications such as electronic skin, ${ }^{1,2}$ soft robotics, ${ }^{3-6}$ adaptive optics, ${ }^{7-9}$ and electro-mechanical transducers, ${ }^{10-12}$ stretchable electrodes are of vital importance. Most existing stretchable electrodes are electronic conductors, such as carbon grease, ${ }^{10-13}$ graphite spray, ${ }^{13}$ carbon nanotubes, ${ }^{14-15}$ conductive particles/polymer composites, ${ }^{16-19}$ and silver nanowires. ${ }^{20-21}$ They are usually not fully transparent or not stretchable enough, which limit their use. Some ionic conductors, however, have recently been proved to meet the requirements. For example, polyacrylamide hydrogel containing sodium chloride $(\mathrm{NaCl})$ as electrolyte has been reported to be fully transparent, highly stretchable and ionic conductive. Hydrogel contains water, and $\mathrm{NaCl}$ could be ionized into sodium cation $\left(\mathrm{Na}^{+}\right)$and lithium anion $\left(\mathrm{Cl}^{-}\right)$, those play the role of conducting ions. The hydrogel has been used as electrode in a transparent loudspeaker. ${ }^{22}$ Another example is a kind of transparent poly(acrylic acid) (PAA) ionogel fabricated by polymerizing acrylic acid in an ionic liquid. The ionogel has a conductivity of $0.22 \mathrm{~S} / \mathrm{m}$, elastic modulus of about $3 \mathrm{kPa}$ and rupturing stretch of about 4.6, and has been used in transparent actuators. $^{23}$

Compared with ionogels, hydrogels containing salt as electrolyte have some advantages such as higher conductivity, much bigger rupturing stretch, lower cost and more ease of fabrication, making them irreplaceable in practical use. In a hydrogel containing salt as electrolyte, salt and water play the two key roles: salt offers conducting ions while water serves as the solvent. A hydrogel containing salt will be conductive as long as it contains water, but the less water it contains the stiffer it will be. Therefore, the water retention capacity of a hydrogel is a fundamental property influencing its other properties. In previous work, however, the hydrogel 
has poor water retention capacity, thus it usually fail to work in a few hours due to drying out. ${ }^{22}$ One way to reduce the rate of water evaporation is to encapsulate the hydrogel, however, it is hard to be realized. Another way is to improve the water retention capacity of the hydrogel itself, but those experiments are lack.

According to modern theory of electrolyte solutions, ${ }^{24,25}$ as salt dissolves into water, it ionizes into cations and anions, meanwhile the ions bond with water molecules forming hydrated ions. Compared with pure water, the ionic hydration effect in aqueous solutions of salt usually causes great changes of their properties, including the volume, resistivity, and freezing point, etc., especially for concentrated solutions. ${ }^{24,26,27}$ Accordingly, it is possible to enhance the water retention capacity of a hydrogel by appropriately selecting the dissolved salt and tuning its concentration. Targeted, we introduce salts with different hydratability and varied concentration into polyacrylamide (PAM) hydrogel, and investigate their water retention capacity as well as their electrical and mechanical properties, aiming to find the most appropriate salt with appropriate concentration to enhance the performance of the hydrogel. Polyacrylamide hydrogels containing sodium chloride $(\mathrm{NaCl})$, lithium chloride $(\mathrm{LiCl})$, potassium acetate $(\mathrm{KAc})$, and magnesium chloride $\left(\mathrm{MgCl}_{2}\right)$ as electrolyte were prepared respectively following a similar procedure as previously reported. ${ }^{22}$ Acrylamide monomer (AM, $2.2 \mathrm{~mol} / \mathrm{L}$ ) and salt powder (NaCl: $4 \mathrm{~mol} / \mathrm{L} ; \mathrm{LiCl} \cdot \mathrm{H}_{2} \mathrm{O}: 4 \sim 12 \mathrm{~mol} / \mathrm{L} ; \mathrm{KAc}: 2 \sim 8 \mathrm{~mol} / \mathrm{L} ; \mathrm{MgCl}_{2} \cdot 6 \mathrm{H}_{2} \mathrm{O}: 2 \sim 4 \mathrm{~mol} / \mathrm{L}$ ) were dissolved in deionized water, then AM monomer was crosslinked by N,N'-methylenebisacrylamide (MBAA, $0.06 \%$ the weight of AM), with ammonium persulfate (AP, $0.17 \%$ the weight of AM) as the initiator and N,N,N',N'-tetramethylenediamine (TEMED, 
$0.05 \% \sim 0.15 \%$ the weight of $\mathrm{AM})$ as the crosslinking accelerator. The solutions were poured into self-made glass molds and gelled in a temperature chamber of $50^{\circ} \mathrm{C}$ for $2 \sim 5$ hours. The as-prepared hydrogels are referred to as PAM_NaCl(i), PAM_LiCl(i), PAM_KAc(i) and PAM_ $\mathrm{MgCl}_{2}(\mathrm{i})$, while i represents the initial dissolved salt concentration.

The hydrogels were cut into cylinder samples with the size of $\phi 30 \mathrm{~mm} \times 2 \mathrm{~mm}$, and kept in a chamber with certain relative humidity and temperature. The morphology changes of the samples in the process were recorded by a digital camera. Figures 1(a)-(c) show the photos of different hydrogel samples kept in a chamber with temperature of $25^{\circ} \mathrm{C}$ and relative humidity of $20 \% \mathrm{RH}$ for different time. The initial dissolved salt concentration is $4 \mathrm{~mol} / \mathrm{L}$. All samples shrink to some degree after about 12 hours, demonstrating that some of the water in the hydrogels have evaporated. Specially, some $\mathrm{NaCl}$ salts dissolve out from PAM_NaCl hydrogel (Figure 1(b)). After about 58 hours, PAM hydrogel without salt becomes stiff; for PAM_NaCl hydrogel, almost all $\mathrm{NaCl}$ salts dissolve out; while for PAM_LiCl, PAM_KAc, and PAM_ $\mathrm{MgCl}_{2}$ hydrogels, they just continue to shrink, but the shrinkage rates decrease a lot (Figure 1(c)), indicating that the evaporation of water becomes slower.

To evaluate the accurate water loss of the hydrogels in the process, their masses were recorded every certain time using an electronic scale, and the water loss at time $=\mathrm{i}$ is calculated by

$$
\text { Water Loss }=-\frac{\text { Mass }(\text { hydrogel }, \text { time }=\mathrm{i})-\text { Mass }(\text { hydrogel }, \text { time }=0)}{\text { Mass }(\text { water }, \text { time }=0)} \text {, }
$$

where Mass (water, time $=0$ ) is calculated by the amount of the raw materials used. 
Figures 2(a)-(c) show the evolutions of water loss with time for polyacrylamide hydrogels containing $\mathrm{LiCl}, \mathrm{KAc}$ and $\mathrm{MgCl}_{2}$ with varied concentration. The samples were kept in a chamber with temperature of $25^{\circ} \mathrm{C}$ and relative humidity of $20 \% \mathrm{RH}$. All the hydrogels exhibit similar characteristics as that, with time going on, their water loss gradually increases till reaching to their steady-state value. At the steady states, for PAM_LiCl hydrogels, as the initial dissolved $\mathrm{LiCl}$ concentration increases from $4 \mathrm{~mol} / \mathrm{L}$ to $12 \mathrm{~mol} / \mathrm{L}$, the water loss decreases from $67 \%$ to $11 \%$ (Figure 2(a)); for PAM_KAc hydrogels, as the initial dissolved KAc concentration increases from $2 \mathrm{~mol} / \mathrm{L}$ to $8 \mathrm{~mol} / \mathrm{L}$, the water loss decreases from $88 \%$ to $58 \%$ (Figure 2(b)); while for PAM_MgCl 2 hydrogels, as the initial dissolved $\mathrm{MgCl}_{2}$ concentration increases from 2 mol/L to 4 $\mathrm{mol} / \mathrm{L}$, the water loss decreases from $74 \%$ to $41 \%$ (Figure 2(c)). Apparently, for hydrogels containing the same kind of salt, their steady-state water loss gets lower with the increase of initial dissolved salt concentration, meaning that their water retention capacity gets better.

The different water retention capacities of these hydrogels result from the difference in ionic hydration $^{24,25}$ degree of the dissolved salts. In a hydrogel, water molecules bonded to ions have to break the bonds to evaporate, while free water molecules evaporate naturally, as shown in Figure (3). Higher ionic hydration degree of the dissolved salt means stronger bond strength between cation/anion-water molecule pairs and more bonded water molecules, resulting in more difficulty of water molecules evaporation or in other words better water retention capacity. We can deduce from the experimental results that the ionic hydration degree of the dissolved salt is controlled by salt species and salt concentration, and that $\mathrm{LiCl}$ salt is more hydratable compared with other investigated salts. 
It is necessary to investigate the variation of water retention capacity for a certain hydrogel when the ambient relative humidity changes. We chose PAM_LiCl(12), PAM_KAc(8), and PAM_MgCl 2 (4) as representatives, due to each of them show the best water retention capacity among the hydrogels containing the same kind of salt (Figures 2(a)-(c)). The evolutions of water loss with time for these hydrogels under different relative humidity $\left(10 \% \mathrm{RH}-30 \% \mathrm{RH}, \sim 25^{\circ} \mathrm{C}\right)$ are shown in Figures 4(a)-(c). As the ambient relative humidity rises from $10 \% \mathrm{RH}$ to $30 \% \mathrm{RH}$, the steady-state water losses of PAM_LiCl(12), PAM_KAc(8) and PAM_MgCl 2 (4) decrease from $28 \%, 77 \%$, and $44 \%$ to $-3.5 \%, 42 \%$, and $32 \%$ respectively. Typically, PAM_LiCl(12) hydrogel exhibits excellent water retention capacity, it can retain over $70 \%$ of its initial water even in environment with relative humidity of only $10 \% \mathrm{RH}$.

After the hydrogel samples reached their steady states respectively, electrical property measurements were carried out subsequently using an impedance analyzer of Agilent E4980A. The conductivity $\sigma$ is calculated by

$$
\sigma=\rho^{-1}=\frac{l}{R S}
$$

where $l$ and $S$ represents the thickness and cross-section area of the sample respectively, and $R$ is the resistance measured by Agilent E4980A.

Figures 5(a)-(c) show the steady-state conductivity of different hydrogels kept in chambers with relative humidity of $20 \% \mathrm{RH}$ and $30 \% \mathrm{RH}\left(25^{\circ} \mathrm{C}\right)$ respectively. For hydrogels containing the same kind of salt, the steady-state conductivity increases as the initial dissolved salt concentration increases, while it decreases as the ambient relative humidity drops. PAM_LiCl(12) hydrogel has the highest conductivity of about $12 \mathrm{~S} / \mathrm{m}$ at $30 \% \mathrm{RH}$ and $10 \mathrm{~S} / \mathrm{m}$ at $20 \% \mathrm{RH}$; 
PAM_KAc(8) hydrogel has conductivity of about $8 \mathrm{~S} / \mathrm{m}$ at $30 \% \mathrm{RH}$ and $6 \mathrm{~S} / \mathrm{m}$ at $20 \% \mathrm{RH}$; while PAM_MgCl${ }_{2}(4)$ hydrogel has conductivity of about $4.5 \mathrm{~S} / \mathrm{m}$ at $30 \% \mathrm{RH}$ and $3 \mathrm{~S} / \mathrm{m}$ at $20 \% \mathrm{RH}$. The results show that with a higher solubility of $\mathrm{LiCl}$, the hydrogel containing $\mathrm{LiCl}$ salt has a much higher conductivity than that of the other two kinds of hydrogels containing KAc and $\mathrm{MgCl}_{2}$.

For mechanical property measurements, the as-prepared hydrogels were cut into cuboid samples with the size of $12 \mathrm{~mm} \times 2 \mathrm{~mm} \times 2 \mathrm{~mm}$, and kept in chambers with certain relative humidity and temperature till they reached their steady states. Then uniaxial tensile tests were performed immediately at a rate of $100 \mathrm{~mm} / \mathrm{min}$ using a tensile machine.

Table I shows the steady-state mechanical properties of different hydrogel samples kept in chambers with relative humidity of $20 \% \mathrm{RH}$ and $30 \% \mathrm{RH}\left(\sim 25^{\circ} \mathrm{C}\right)$. The Young's modulus is got from the stretch-stress curve within small stretch $(<1)$. Under relative humidity of $30 \% \mathrm{RH}$ $\left(\sim 25^{\circ} \mathrm{C}\right)$, all hydrogels have low Young's modulus ( $\left.<3 \mathrm{kPa}\right)$, but PAM_LiCl and PAM_MgCl 2 hydrogels have large fracture stretch (>20), while PAM_KAc hydrogels have smaller fracture stretch, especially that PAM_KAc(8) only has a fracture stretch of 7. As the ambient relative humidity drops to $20 \% \mathrm{RH}\left(\sim 25^{\circ} \mathrm{C}\right)$, the Young's modulus and fracture stretch of PAM_LiCl hydrogels do not change too much, but the Young's modulus of PAM_KAc hydrogels increases and its fracture stretch decreases further, while the Young's modulus of PAM_MgCl${ }_{2}$ hydrogels increases a lot $(>5 \mathrm{kPa})$ despite that they still have large fracture stretch $(\sim 20)$. Compared with PAM_KAc and PAM_MgCl 2 hydrogels, PAM_LiCl hydrogels exhibit the best mechanical properties with low Young's modulus $(<3 \mathrm{kPa})$ and large fracture stretch $(>20)$. 
When the ambient relative humidity drops to $10 \% \mathrm{RH}$, it is hard to measure the conductivity and mechanical properties of the hydrogels since the air relative humidity is rarely as low as $10 \%$ RH. However, from the water retention capacity measurement results we can see that the water loss of the hydrogels does not increase too much when the ambient relative humidity drops from $20 \% \mathrm{RH}$ to $10 \% \mathrm{RH}$ (Figures $4(\mathrm{a})-(\mathrm{c})$ ), so we can deduce that the conductivity and mechanical properties of the hydrogels will not deteriorate too much either.

Lastly, we measured the electric temperature dependency of the resistance and conductivity of PAM, PAM_LiCl(12), PAM_KAc(8) and PAM_MgCl 2 (4) hydrogel, as shown in Figures 6(a)-(d). The as-prepared hydrogels were cut into cylinder samples with the size of $\phi 30 \mathrm{~mm} \times 2 \mathrm{~mm}$, and gold foil electrodes were pasted onto the samples. The samples were then kept in a temperature chamber with the temperature varying from $-100^{\circ} \mathrm{C}$ to $100^{\circ} \mathrm{C}$. Impedance measurements were carried out using Novocontrol Concept 40 broadband dielectric/impedance spectrometer. Conductivity of the samples is calculated using Equation (2). As ambient temperature drops, the resistance of the hydrogels normally increases gradually at first, and then increases sharply when the temperature drops below a critical point, while the conductivity of the hydrogel decreases to near zero simultaneously. For PAM hydrogel without salt, at a critical temperature of $0^{\circ} \mathrm{C}$, the hydrogel has a resistance of $172 \Omega$ and a conductivity of $0.017 \mathrm{~S} / \mathrm{m}$. At temperature of $-2^{\circ} \mathrm{C}$, its resistance increases sharply to about $1 \mathrm{k} \Omega$ while its conductivity decreases to less than $0.003 \mathrm{~S} / \mathrm{m}$ (Figure $6(\mathrm{a})$ ). Since the freezing point of pure water is $0^{\circ} \mathrm{C}$, it is reasonable to deduce that the freezing point of PAM hydrogel is near $0^{\circ} \mathrm{C}$. For other samples, according to their resistance/conductivity-temperature curves and the behavior of the 
resistance/conductivity of PAM hydrogel near the freezing point, we can deduce that the freezing points of PAM_LiCl(12), PAM_KAc(8) and PAM_ $\mathrm{MgCl}_{2}(4)$ hydrogel is near $-80^{\circ} \mathrm{C},-60^{\circ} \mathrm{C}$ and $-20^{\circ} \mathrm{C}$ respectively (Figures $6(\mathrm{~b})-(\mathrm{c})$ ). These results show that the incorporation of salt can cause great decreases of the freezing points of the hydrogels.

In summary, we study the influence of both salt species and salt concentration on the water retention capacities as well as the electrical and mechanical properties of polyacrylamide hydrogels containing salts as electrolyte. In terms of improving water retention capacity of the hydrogel, $\mathrm{NaCl}$ is less effective, while $\mathrm{LiCl}, \mathrm{KAc}$, and $\mathrm{MgCl}_{2}$ are effective in different level. For hydrogels containing the latter three kinds of salt, their overall performances get better with the increase of initial dissolved salt concentration. Specially, $\mathrm{LiCl}$ is proved to be the most effective salt for water retaining: with an initial dissolved concentration of $12 \mathrm{~mol} / \mathrm{L}$, over $70 \%$ of the water in PAM_LiCl hydrogel can be retained even in environment with relative humidity of only $10 \%$ RH. Apart from the excellent water retention capacity, the hydrogel also shows quite good electrical properties (high conductivity of $\sim 10 \mathrm{~S} / \mathrm{m}$, low freezing point of $\sim-80^{\circ} \mathrm{C}$ ) and good mechanical properties (low elastic modulus of $\sim 3 \mathrm{kPa}$, large fracture stretch of over 20). These results will be beneficial for broadening the application fields of hydrogels.

This research is supported by Natural Science Foundation of China (grants 61025002, 11072185, 11372239 and 11321062). ZS acknowledges the support of NSF MRSEC (DMR-0820484) and visiting appointment at the International Center for Applied Mechanics. 


\section{Reference}

1. S. Bauer, Nature Mater. 12, 871 (2013).

2. C. Wang, D. Hwang, Z. Yu, K. Takei, J. Park, T. Chen, B. Ma and A. Javey, Nature Mater. 12, 899 (2013).

3. S. Kim, C. Laschi, and B. Trimmer, Trends Biotechnol. 31, 23 (2013).

4. I. A. Anderson, T. A. Gisby, T. G. McKay, B. M. O'Brien and E. P. Calius, J. Appl. Phys. 112, 041101 (2012).

5. H. R. Choi, K. Jung, S. Ryew, J. D. Nam, J. Jeon, J. C. Koo and K. Tanie, IEEE/AAME Trans. Mechatron. 10, $581(2005)$.

6. P. Brochu and Q. B. Pei, Macromol. Rapid Commun. 31, 10 (2010).

7. F. Carpi, G. Frediani, S. Turco and D. De Rossi, Adv. Funct. Mater. 21, 4152 (2011).

8. S.-i. Son, D. Pugal, T. Hwang, H. R. Choi, J. C. Koo, Y. Lee, K. Kim and J.-D. Nam, Appl. Opt. 51, 2987 (2012).

9. S. Shian, R. M. Diebold and D. R. Clarke, Opt. Express 21, 8669 (2013).

10. R. Pelrine, R. Kornbluh, Q. B. Pei and J. Joseph, Science 287, 836 (2000).

11. R. Pelrine, R. Kornbluh, J. Joseph, R. Heydt, Q. B. Pei and S. Chiba, Mater. Sci. and Eng. C 11, 89 (2000).

12. R. Shankar, T. K. Ghosh and R. J. Spontak, Soft Matter 3, 1116 (2007).

13. F. Carpi, P. Chiarelli, A. Mazzoldi and D. De Rossi, Sens. Actuators, A 107, 85 (2003).

14. L. Hu, W. Yuan, P. Brochu, G. Gruner, Q. Pei, Appl. Phys. Lett. 94, 161108 (2009).

15. V. Scardaci, R. Coull, J. N. Coleman, Appl. Phys. Lett. 97, 023114 (2010).

16. M. Bozlar, C. Punckt, S. Korkut, J. Zhu, C. C. Foo, Z. Suo and I. A. Aksay, Appl. Phys. Lett. 101, 091907 (2012).

17. S. Rosset, M. Niklaus, P. Dubois and H. R. Shea, Adv. Funct. Mater. 19, 470 (2009). 
18. D. C. Hyun, M. Park, C. Park, B. Kim, Y. Xia, J. H. Hur, J. M. Kim, J. J. Park and U. Jeong, Adv. Mater. 23, 2946 (2011).

19. S. Michel, B. T. T. Chu, S. Grimm, F. A. Nueesch, A. Borgschulte and D. M. Opris, J. Mater. Chem. 22,20736 (2012).

20. Z. Yu, Q. Zhang, L. Li, Q. Chen, X. Niu, J. Liu, and Q. Pei, Adv. Mater. 23, 664 (2011).

21. W. Hu , X. Niu, L. Li , Q. Chen, S. Yun, Z. Yu, and Q. Pei, Nanotechnology 23, 344002 (2012).

22. C. Keplinger, J.-Y. Sun, C. C. Foo, P. Rothemund, G. M. Whitesides and Z. Suo, Science (New York, N.Y.) 341, 984 (2013).

23. B. Chen, J. J. Lu, C. H. Yang, J. Zhou, Y. M. Chen, and Z. Suo, ACS Appl. Mater. \& Interfaces 6, 7840 (2014).

24. Stokes and Robinson, J. Amer. Chem. Soc. 70, 1870 (1948).

25. G. C. Jian. Electrolyte Solutions and Ion Reactions [M]. Beijing: China Youth Press, 1985. 1-11.

26. Rodebush, W. H., J. Am. Chem. Soc. 40, 1204 (1918).

27. E. Glueckauf, Trans. Faraday Soc. 51, 1235 (1955). 


\section{Figure Captions}

FIG. 1. Photos of hydrogel samples kept in chamber with temperature of $25^{\circ} \mathrm{C}$ and relative humidity of 20\% RH for different time: (a) 0 hour; (b) 12 hours; (c) 58 hours. The initial dissolved salt concentration is $4 \mathrm{~mol} / \mathrm{L}$. The transparent hydrogels are put on yellow slippy silicone papers in order not to constrain their shrink.

FIG. 2. Evolutions of water loss with time for different hydrogels kept in chamber with temperature of $25^{\circ} \mathrm{C}$ and relative humidity of $30 \%$ RH: (a) PAM_LiCl(i); (b) PAM_KAc(i); (c) PAM_MgCl 2 (i).

FIG. 3. Schematic of the hydration of $\mathrm{LiCl}$ in water.

FIG. 4. Evolutions of water loss with time for hydrogels with high content of salt kept in chambers with chamber of $25^{\circ} \mathrm{C}$ and different relative humidity: (a) PAM_LiCl(12); (b) PAM_KAc(8); (c) PAM_MgCl $2(4)$.

FIG. 5 Conductivity of hydrogels containing different salts with varied concentration after they reached their steady states when kept in chambers with relative humidity of $20 \% \mathrm{RH}$ and $30 \%$ RH ( 25ㄷ): (a) PAM_LiCl; (b) PAM_KAc; (c) PAM_MgCl 2 .

FIG. 6 Temperature dependency of the resistivity and conductivity of different hydrogels: (a) PAM hydrogel; (b) PAM_LiCl(12) hydrogel; (c) PAM_KAc(8) hydrogel; (d) PAM_MgCl 2 (4) hydrogel.

TABLE I. Mechanical properties of different hydrogel samples after they reach their steady states 
when kept in chambers with different relative humidity $\left(\sim 25^{\circ} \mathrm{C}\right)$. The Young's modulus refers to the average Young's modulus of each sample within small stretch $(<1)$.

\begin{tabular}{|c|c|c|c|c|c|c|c|}
\hline Condition & Parameter & $\begin{array}{c}\text { PAM_LiCl } \\
(8)\end{array}$ & $\begin{array}{c}\text { PAM_LiCl } \\
\text { (12) }\end{array}$ & $\begin{array}{c}\text { PAM_KAc } \\
(6)\end{array}$ & $\begin{array}{c}\text { PAM_KAc } \\
(8)\end{array}$ & $\begin{array}{c}\text { PAM_MgCl} \\
\text { (3) }\end{array}$ & $\begin{array}{c}\text { PAM_MgCl}{ }_{2} \\
\text { (4) }\end{array}$ \\
\hline \multirow{2}{*}{$\begin{array}{c}25^{\circ} \mathrm{C} \\
20 \% \mathrm{RH}\end{array}$} & $\begin{array}{c}\text { Young's } \\
\text { modulus }(\mathrm{kPa})\end{array}$ & 3.0 & 1.8 & 4.4 & 1.0 & 13.3 & 6.4 \\
\hline & Fracture stretch & $>20$ & $>20$ & 11 & 5 & 20 & 19 \\
\hline \multirow{2}{*}{$\begin{array}{c}25^{\circ} \mathrm{C}, \\
30 \% \mathrm{RH}\end{array}$} & $\begin{array}{c}\text { Young's } \\
\text { modulus }(\mathrm{kPa})\end{array}$ & 2.5 & 1.7 & 1.3 & 0.6 & 2.1 & 1.2 \\
\hline & Fracture stretch & $>20$ & $>20$ & 16 & 7 & $>20$ & $>20$ \\
\hline
\end{tabular}




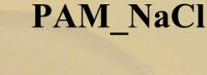

\section{(b) 12 hours}

\section{PAM}

PAM_LiCI

PAM_KAc

PAM_MgCl ${ }_{2}$

PAM_NaCl

(c) 58 hours

PAM

PAM_LiCl

PAM_KAc

PAM_MgCl,

PAM_NaCl 


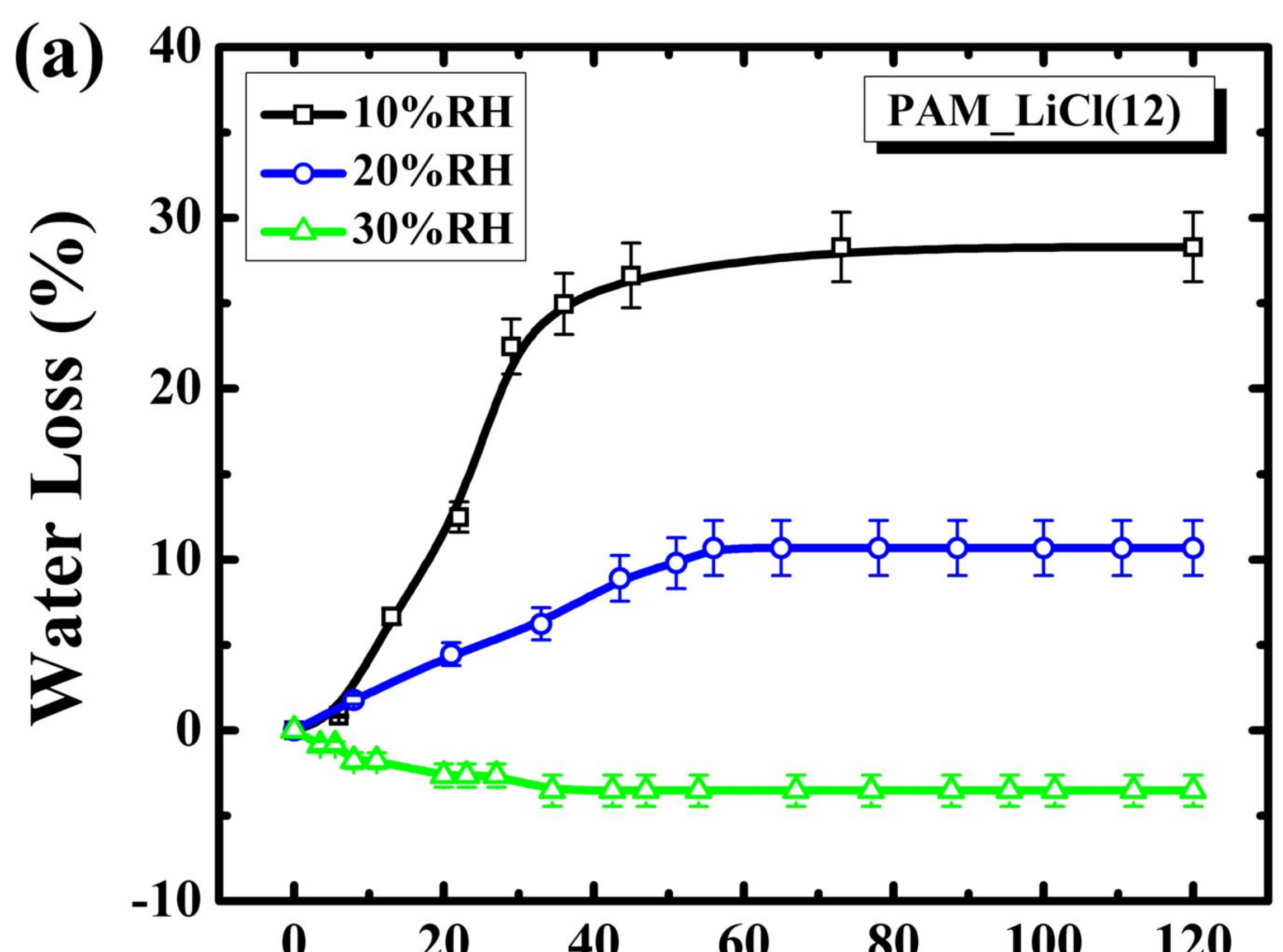

Time (h)

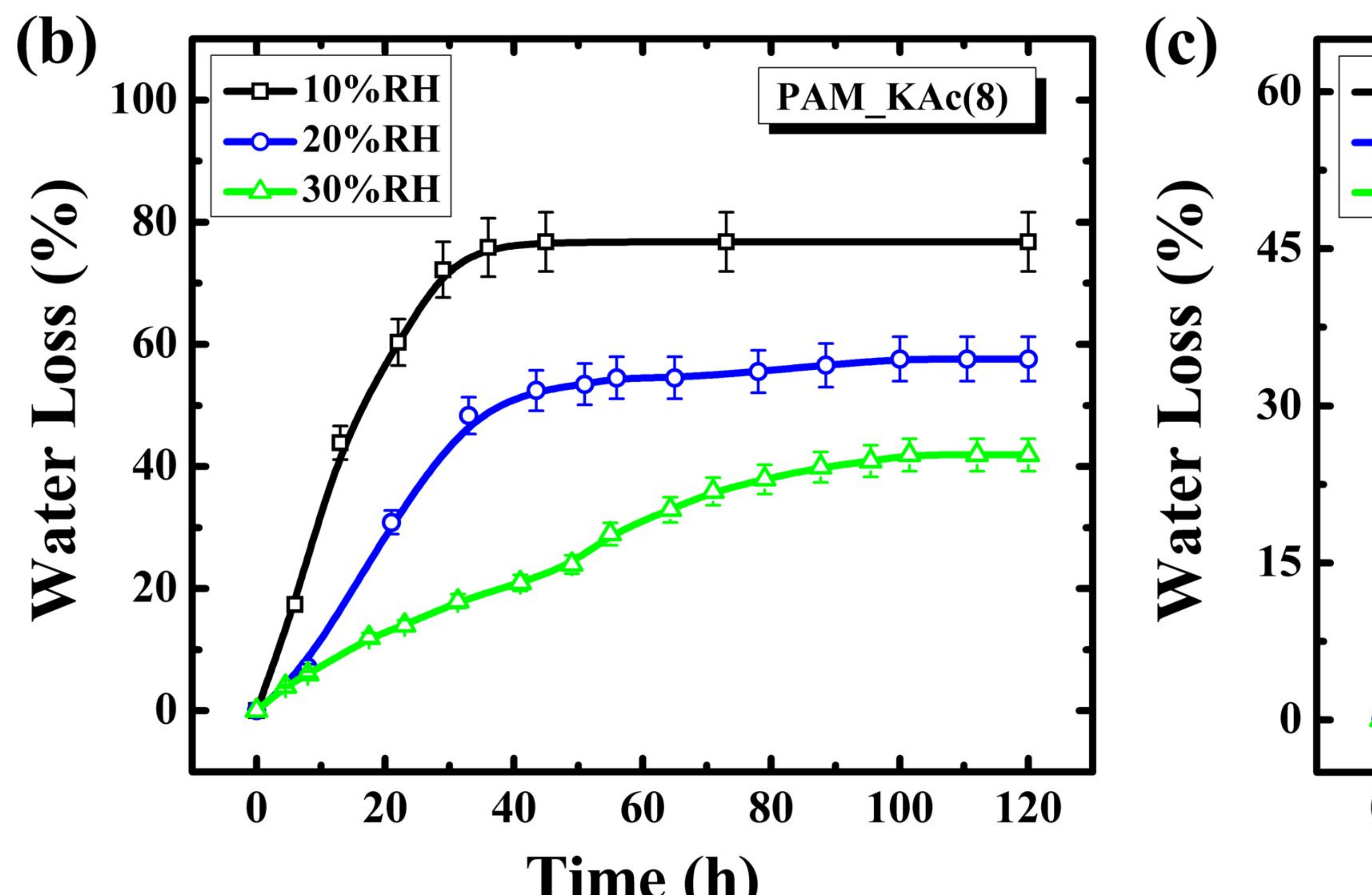

Time (h)

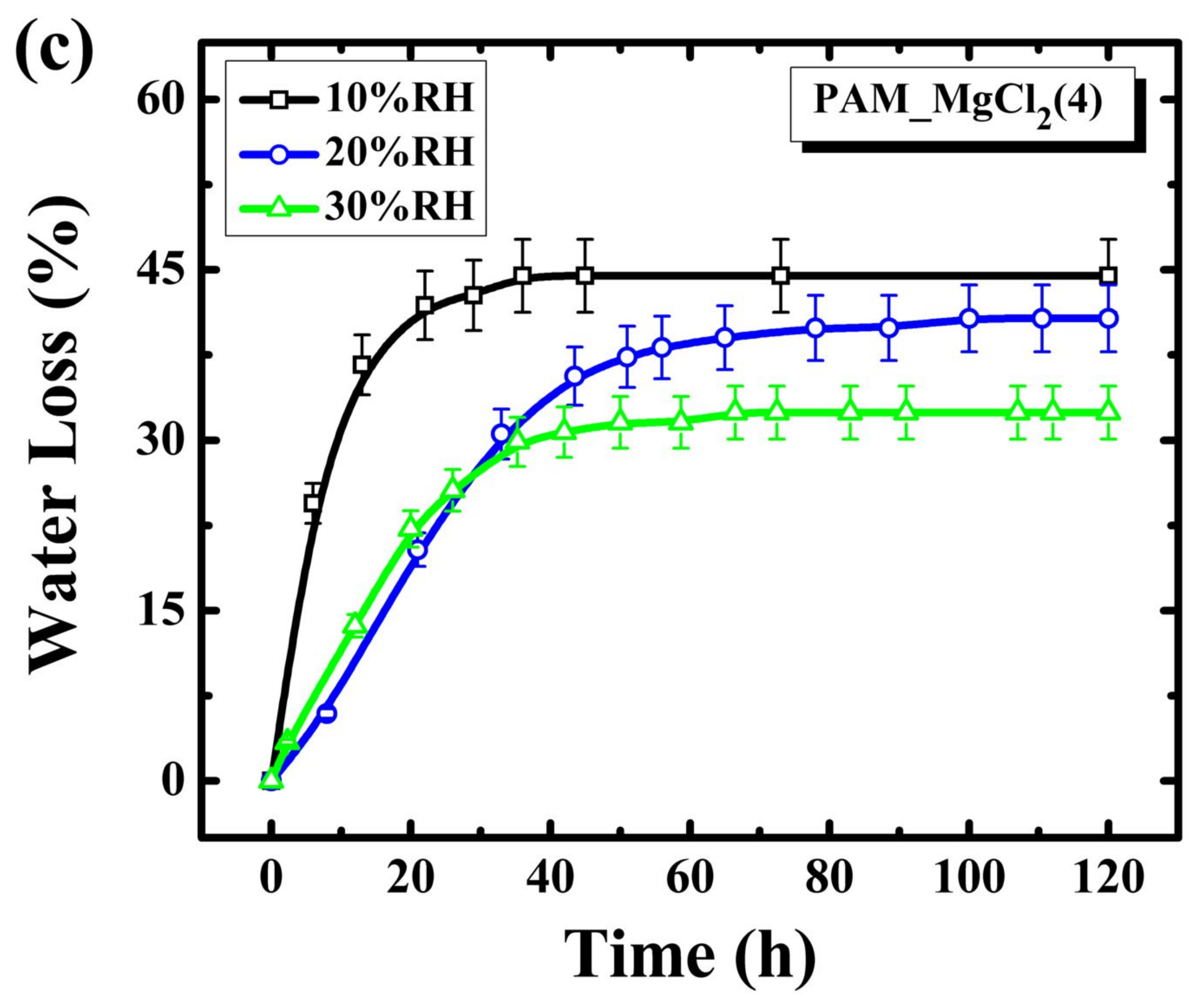

Time (h) 


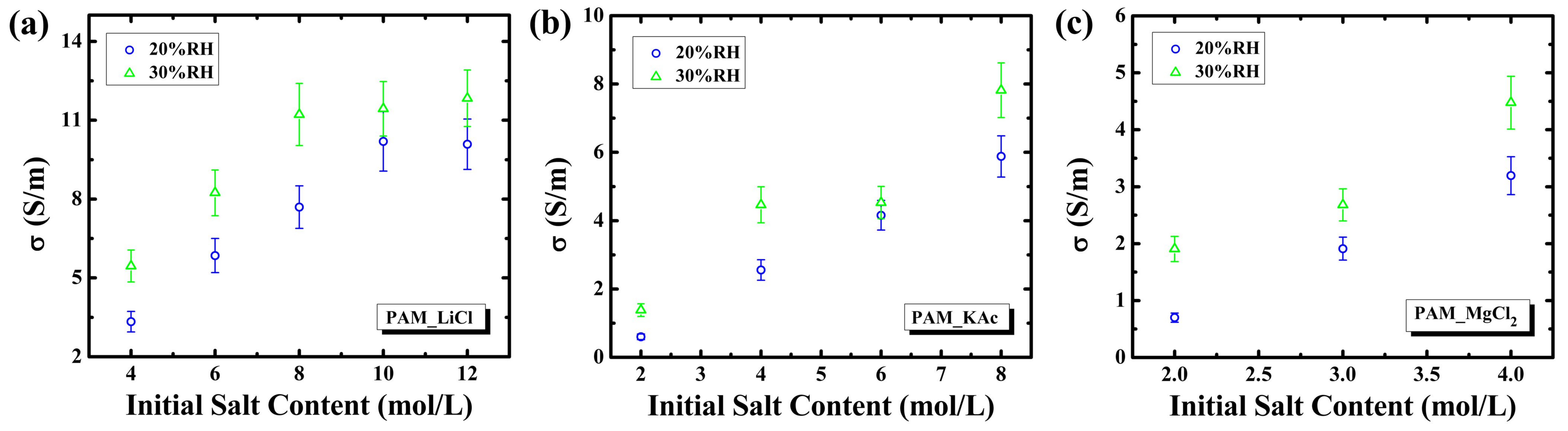

\section{Initial Salt Content $(\mathrm{mol} / \mathrm{L})$}

(c) $\sqrt[6]{1}$

5. $\triangle 30 \% \mathrm{RH}$

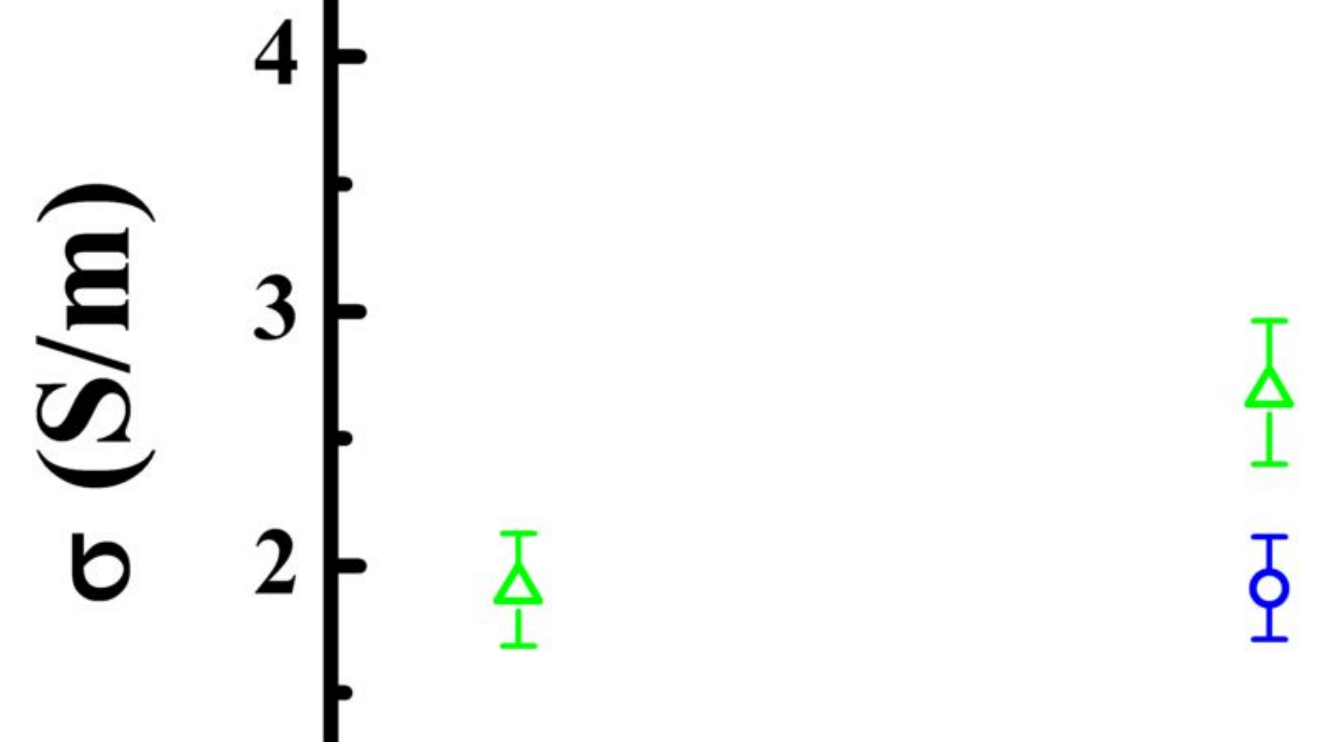

PAM_MgCl 2
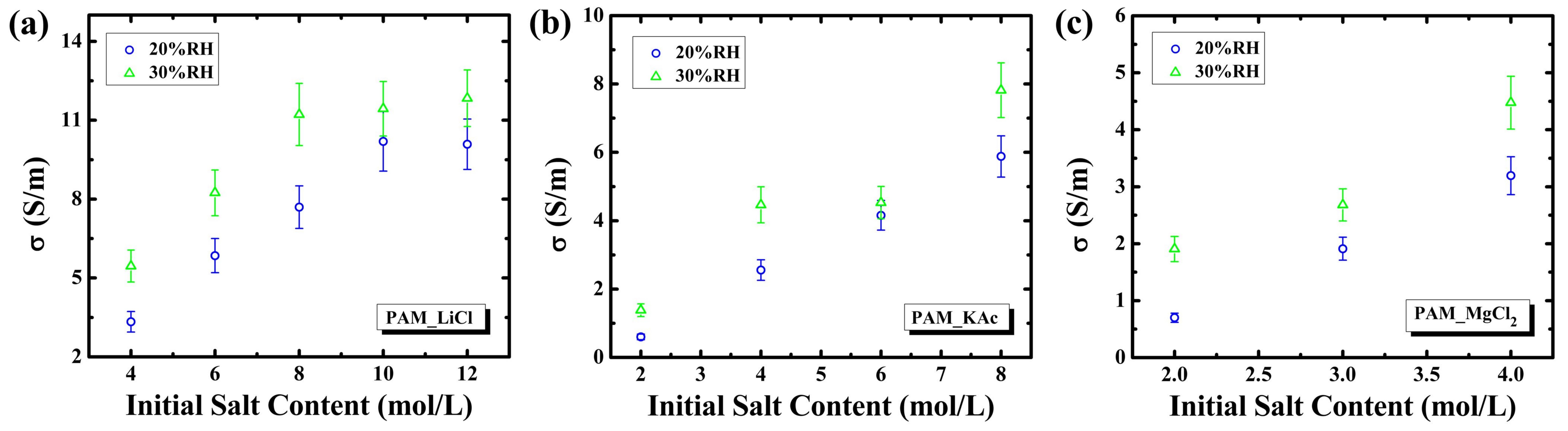
()

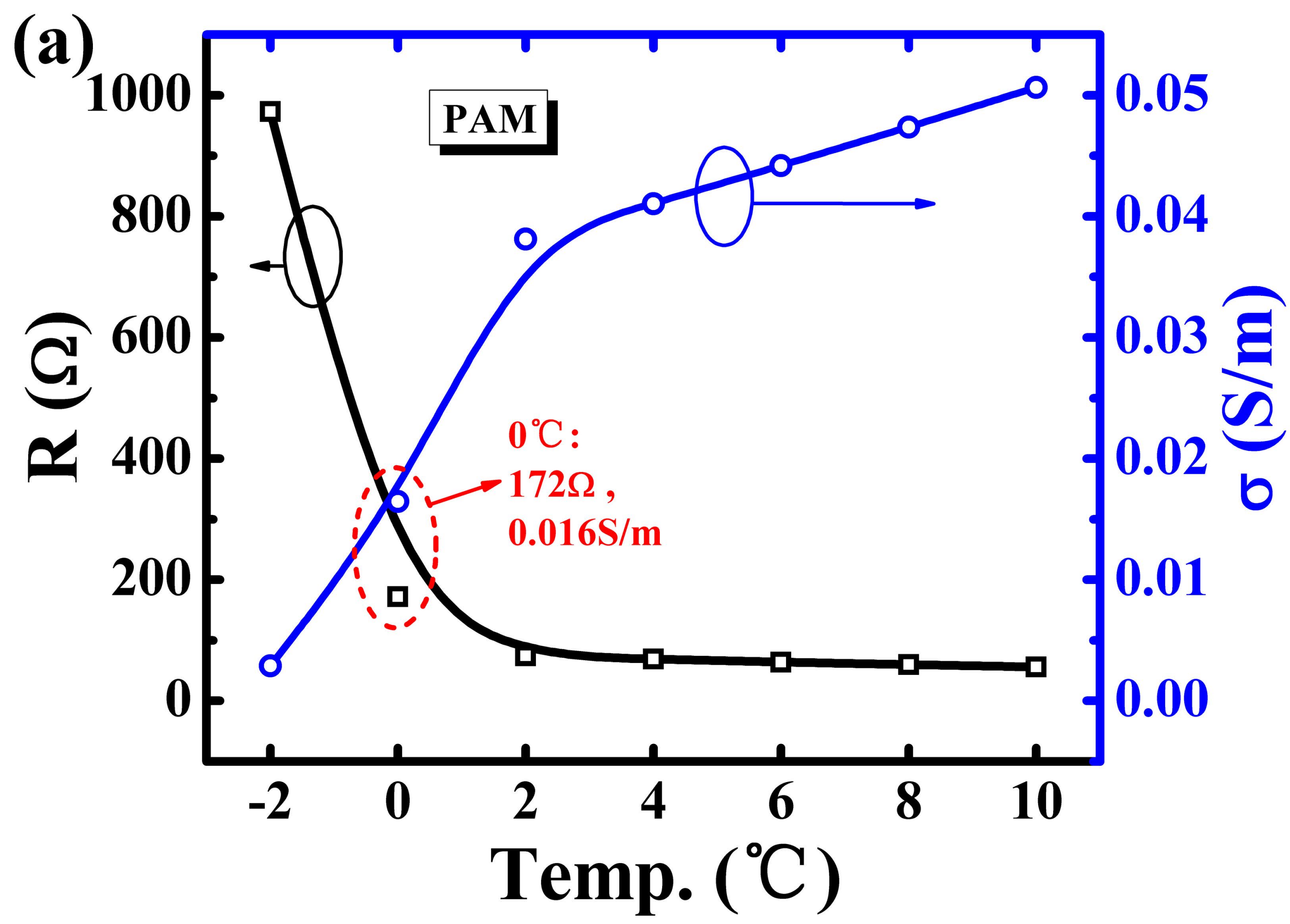

$$
\text { (c) }
$$

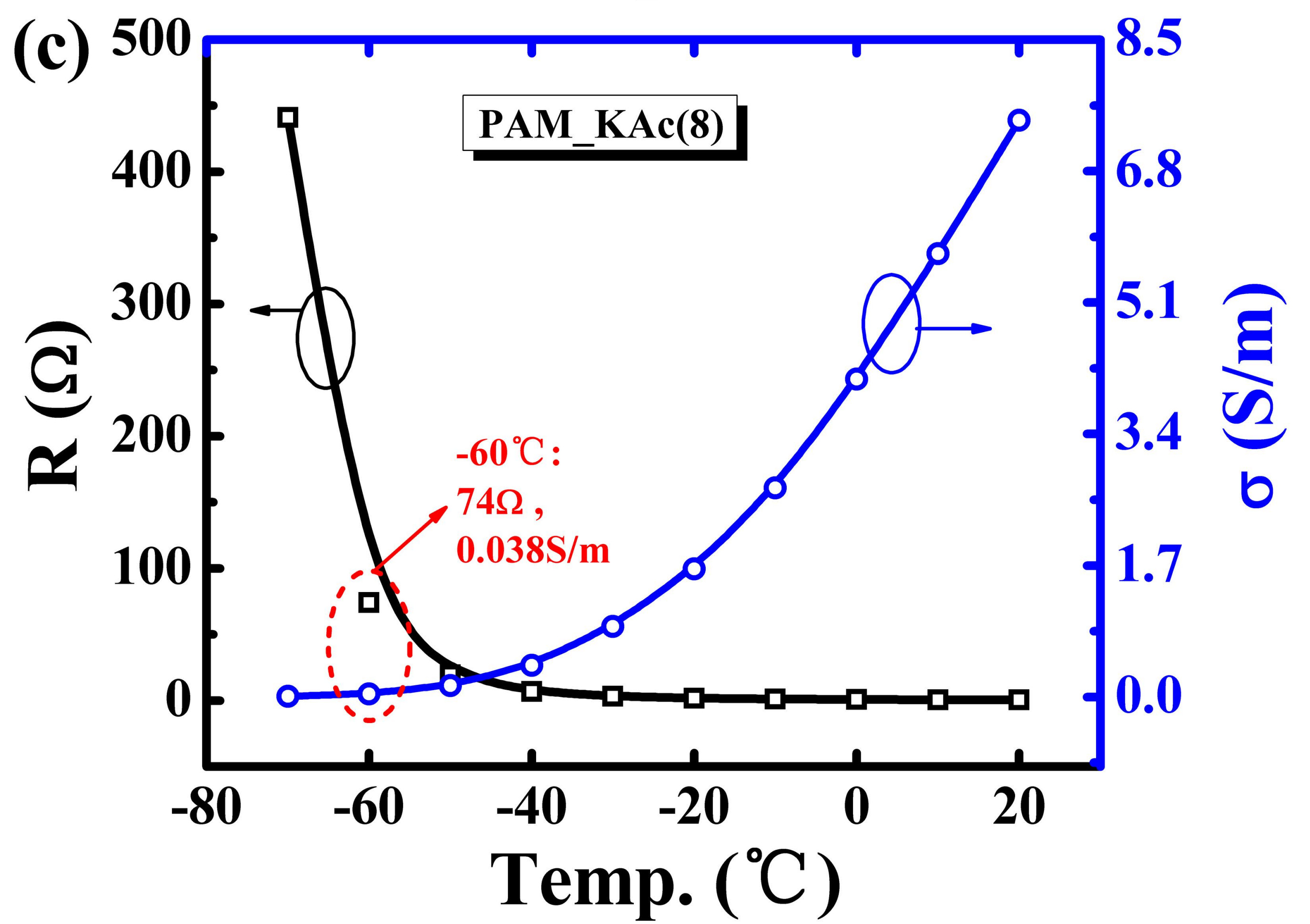

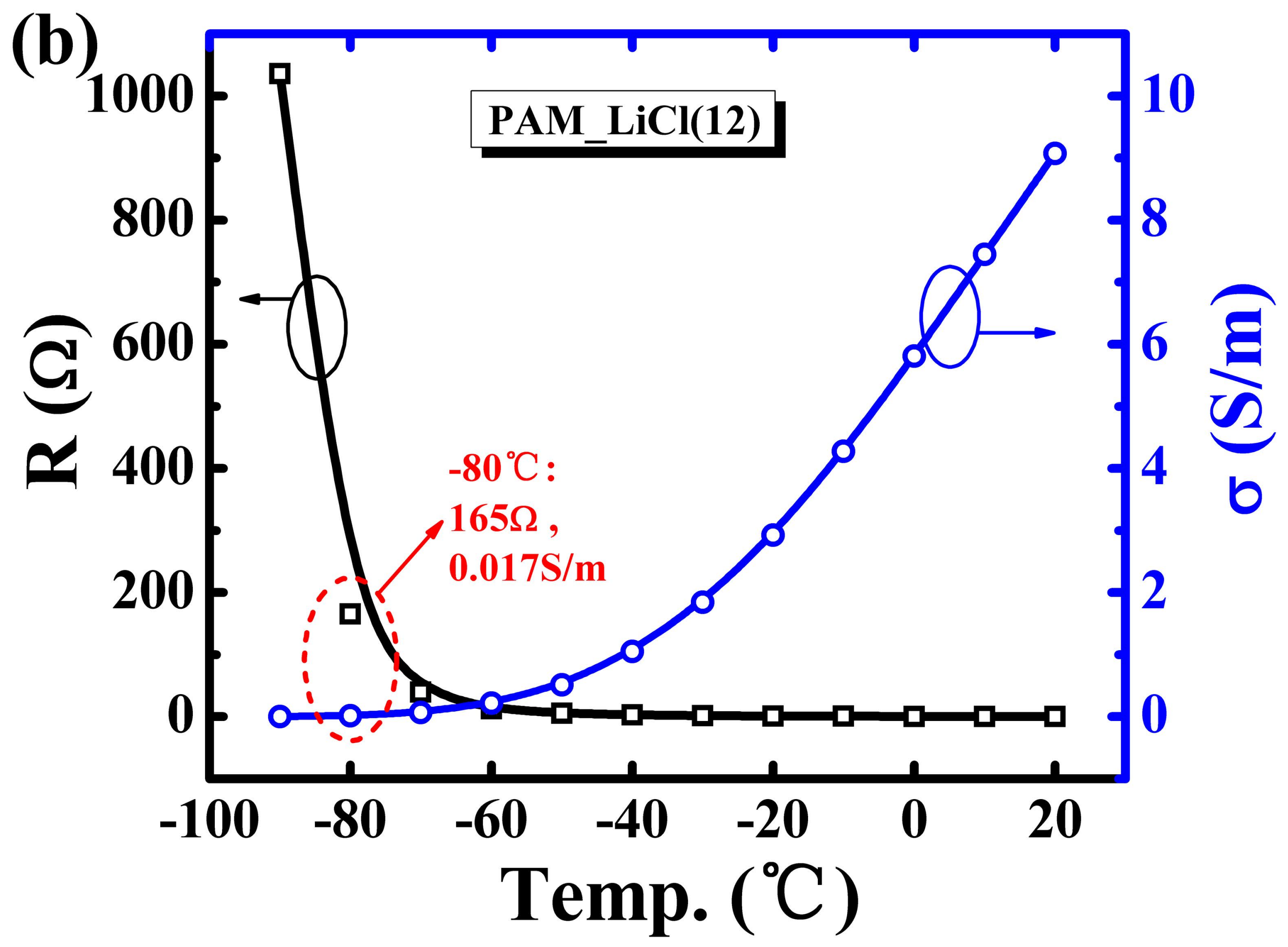

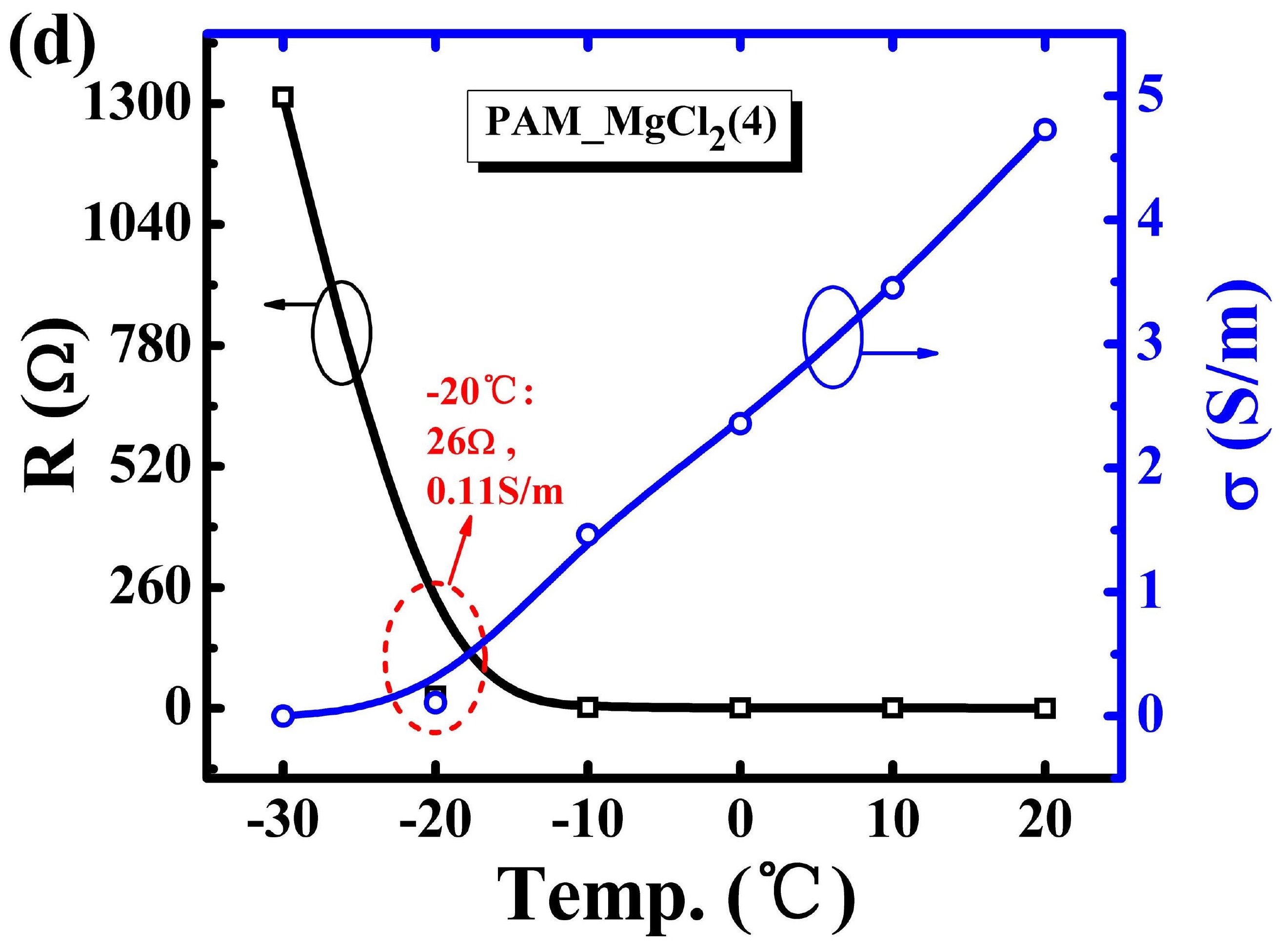

